\title{
Impact of clinical supervision on job satisfaction and emotional competence of nurses
}

\author{
Impacto da supervisão clínica na satisfação profissional e na competência emocional dos enfermeiros \\ Impacto de la supervisión clínica en la satisfacción laboral y en la competencia emocional de los enfermeros
}

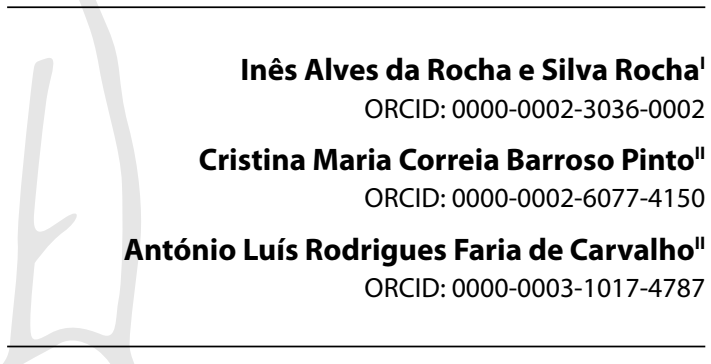

'Universidade do Porto, Instituto de Ciências Biomédicas Abel Salazar. Porto, Portugal.

"Escola Superior de Enfermagem do Porto-CINTESIS.

Porto, Portugal.

How to cite this article: Rocha I, Pinto C, Carvalho L. Impact of clinical supervision on job satisfaction and emotional competence of nurses.

Rev Bras Enferm. 2021;74(6):e20210125. https://doi.org/10.1590/0034-7167-2021-0125

Corresponding author:

Inês Alves da Rocha e Silva Rocha

E-mail: inesarsrocha@gmail.com

EDITOR IN CHIEF: Antonio José de Almeida Filho ASSOCIATE EDITOR: Elizabete Salvador

Submission: $02-17-2021$

Approval: 04-12-2021

\section{ABSTRACT}

Objective: To evaluate the impact of implementing the SafeCare clinical supervision model on nurses' job satisfaction and emotional competence profile. Methods: This is a quasi-experimental study, with a sample of 28 nurses from a hospital in northern Portugal. A self-administered questionnaire was applied, used as pre and post-test, which included: sociodemographic and professional characterization; "Job Satisfaction Scale"; and "Veiga Emotional Competence Scale". We conducted descriptive statistical analysis and the Wilcoxon Test. Results: A significant decrease in the nurses' satisfaction with hierarchical superior was observed in the post-test. No significant differences were found in the nurses' job satisfaction and emotional competence after the implementation of the SafeCare Model. Conclusion: The SafeCare Model needs improvement, suggesting increasing the amount of training time administered to nurses and strengthening the healthcare institution's link to the Model. Descriptors: Nursing; Job Satisfaction; Emotional Intelligence; Mentors; Clinical Nursing Research.

\section{RESUMO}

Objetivo: Avaliar o impacto da implementação do Modelo de supervisão clínica SafeCare na satisfação profissional e no perfil de competência emocional dos enfermeiros. Métodos: Estudo quase-experimental, com uma amostra de 28 enfermeiros de um hospital do norte de Portugal. Aplicou-se um questionário de autopreenchimento, utilizado como pré e pósteste, que engloba caracterização sociodemográfica e profissional, "Escala da Satisfação Profissional" e "Escala Veiga de Competência Emocional". Realizaram-se análise estatística descritiva e Teste de Wilcoxon. Resultados: Observou-se uma diminuição significativa na satisfação dos enfermeiros com o superior hierárquico no pós-teste. Não se verificaram diferenças significativas na satisfação profissional e na competência emocional dos enfermeiros após a implementação do Modelo SafeCare. Conclusão: É necessário aperfeiçoar o Modelo SafeCare, sugerindo que se aumente o tempo de formação administrada aos enfermeiros e fortaleça o vínculo da instituição de saúde ao Modelo.

Descritores: Enfermagem; Satisfação no Emprego; Inteligência Emocional; Mentores; Pesquisa em Enfermagem Clínica.

\section{RESUMEN}

Objetivo: Evaluar el impacto de la aplicación del Modelo de supervisión clínica SafeCare en la satisfacción laboral y en el perfil de competencia emocional de los enfermeros. Métodos: Se trata de un estudio cuasi experimental, realizado con una muestra de 28 enfermeros de un hospital del norte de Portugal. Se aplicó un cuestionario autocompletado como pre y pos test, que incluía la caracterización sociodemográfica y profesional, la "Escala de Satisfacción Laboral" y la "Escala Veiga de Competencia Emocional". Se llevaron a cabo análisis estadísticos descriptivos y la prueba de Wilcoxon. Resultados: Fue posible observar una disminución significativa de la satisfacción de los enfermeros con su superior jerárquico en la prueba posterior al test. No se encontraron diferencias significativas en la satisfacción laboral y en la competencia emocional de los enfermeros tras la aplicación del modelo SafeCare. Conclusión: Es necesario perfeccionar el Modelo SafeCare, aumentando la cantidad de formación impartida a los enfermeros y reforzando el vínculo de la institución sanitaria con el Modelo. Descriptores: Enfermería; Satisfacción Laboral; Inteligencia Emocional; Mentores; Investigación en Enfermería Clínica. 


\section{INTRODUCTION}

Clinical supervision in Nursing has been regularly studied by nurses since $1980^{(1)}$, and may be defined as a formal process of monitoring professional practice, which aims to promote autonomous decision-making, valuing the person's protection and care safety, through methods of reflection and analysis of clinical practice ${ }^{(2)}$, being considered essential for a quality experience of health professionals ${ }^{(3)}$. The core of clinical supervision is the safety and well-being of users and their families, and it also plays a key role in supporting the needs and well-being of professionals, which justifies its implementation and maintenance ${ }^{(4)}$.

In this scenario, there are several models of clinical supervision, which denotes the lack of consensus on the best way to put clinical supervision into practice in clinical contexts ${ }^{(5)}$. Some studies indicate that the clinical supervision models developed so far have not been able to respond to the diversity of practice settings and the potential of multiple team $\mathrm{s}^{(6)}$. A recurrent limitation in the research produced in this area is related to the lack of clinical's supervision operationalization, namely the unclear definition regarding the participants, quantity, and content of clinical supervision managed ${ }^{(7)}$. In Portugal, given the absence of a model that proved to be practical for nurses, the SafeCare Clinical Supervision Model was created based on the Contextualized Nursing Clinical Supervision Model, which has been improved over time ${ }^{(8)}$. The SafeCare Model is a nursing clinical supervision model that aims to contribute to the promotion of safety and quality on nursing care, with the purpose of developing, in nurses, a set of skills that allow them to have a professional practice of excellence, by identifying intervention areas ${ }^{(6)}$.

Literature has suggested that clinical supervision allows professionals to develop knowledge and skills essential to achieving higher levels of nursing care and that better care increases professional development, a fact that contributes to their increased job satisfaction ${ }^{(1)}$. Job satisfaction can be defined as the worker's emotional response to different work-related factors, resulting in seeking pleasure, comfort, confidence, rewards, personal growth, progression, and recognition, with monetary value as compensation ${ }^{(9)}$. Professional satisfaction influences personal satisfaction, and satisfied individuals are motivated and balanced, physically and emotionally, and will easily provide better quality health care ${ }^{(10)}$. Better nurse-to-patient ratios, more training for nurses, and greater involvement in the organization's decision-making and policies lead to better productivity and satisfaction levels, favoring the results of nursing care and the healthcare organization ${ }^{(11)}$. Clinical supervision also allows individuals to develop and maintain healthier emotional levels, enhancing a work culture that is emotionally more favorable to the performance of health professionals $s^{(5)}$. The phenomenon of nurses' emotional competence has a prominent place in the nursing profession, as it allows nurses to understand the impact of emotions on others and sometimes they contain their own emotions so as not to be disruptive to others, avoiding potential conflicts ${ }^{(12)}$. The concept of emotional competence was created from the mixed model of emotional intelligence ${ }^{(13)}$, referring to the ability of individuals to be aware of their own emotions and reactions and to adjust the way they interact with others ${ }^{(14)}$. Regarding the care provided, a nurse who has emotional competence will find it easier to develop a positive therapeutic relationship, since they are able to anticipate users' emotional reactions ${ }^{(15)}$.

The implementation of clinical supervision models that focus on these two variables (job satisfaction and emotional competence) has an inestimable value since it can contribute to identifying needs at workplaces and planning of possible solutions, with repercussions improvements in health services, safety, and quality of the care provided ${ }^{(16)}$.

The SafeCare Model, created by a group of Portuguese researchers of the SafeCare Project ${ }^{(6)}$, emerged as a response to the lack of a clinical supervision models that could respond to the diversity of clinical practice contexts; in other words, there was a need to create a nursing clinical supervision model focused on the real needs and interests felt by nurses. The fact that, during its implementation, used instruments that allow data collection from a quantitative perspective goes in accordance with what the evidence has suggested as there is a scarcity of clinical supervision studies with a quantitative methodology, making it essential to conduct such studies in order to develop and sustain the evidence produced on this topic ${ }^{(1)}$. The SafeCare Model also offers the added value of operationalizing and clarifying the aspects inherent to its application in practice contexts, as most studies in this field do not mention how to operationalize clinical supervision, making its replication unfeasible a posteriori ${ }^{(5,7)}$. Thus, the SafeCare Model has four stages: situation diagnosis; identification of needs in clinical supervision; implementation of the SafeCare Model; and assessment of results. In the first stage (situation diagnosis), taking into account the visible needs in the care context, the variables for the study were defined together with the nurse managers (nurse director, nurse services supervisor, and head nurses). In this stage, we applied the data collection questionnaire to all nurses in the context. In the second stage (identification of needs in clinical supervision), meetings were held with nurses from the contexts to identify which aspects, in their opinion, required change: they can be intrinsic, of a personal nature, or extrinsic, related to service organization and care delivery. This stage is extremely important, since it allowed adapting the Model to the context where it was being deployed. The third stage (implementation of the SafeCare Model) concerns the intervention, in which group supervision sessions took place in order to promote reflection and discussion on the clinical supervision needs identified by nurses and provided training on the variables defined in the situation diagnosis stage. Finally, the fourth stage (assessment of results) aimed to evaluate the effectiveness of implementing the SafeCare Model, which is carried out through the application of the same questionnaire used in stage 1 regarding job satisfaction and emotional competence to all nurses.

\section{OBJECTIVE}

To assess the impact of implementing the SafeCare clinical supervision model on nurses' job satisfaction and emotional competence profile. 


\section{METHODS}

\section{Ethical Aspects}

In order to carry this study out, permission was obtained from the Board of Directors and the Ethics Committee for Health of the hospital where the data were collected. The scales' authors included in the data collection questionnaire authorized its use. Each nurse was asked to sign the informed consent form and to fill out the supervision contract so that all participants would formally assume clinical supervision.

\section{Design, setting and period}

This is a quasi-experimental study, pre-test post-test type, with no control group, since it aims to identify the impact of an intervention (in this case, the implementation of the SafeCare Model) on the variables under study (job satisfaction and emotional competence). The study was developed from 2017 to 2019, in two medical services of a hospital with high care complexity located in northern Portugal.

\section{Sample size; inclusion criteria}

The sample initially consisted of 44 nurses (the total number of nurses in the services), but due to absenteeism related to unsafe pregnancy $(n=6 ; 13,6 \%)$, service transfer $(n=4 ; 9,1 \%)$, health institution relocating ( $n=3 ; 6,8 \%)$, and long-term sickness absenteeism ( $n=3 ; 6,8 \%$ ), it was only possible to pair 28 nurses who completed the study. For the definition of the sample, the inclusion criteria included working as nurses or expert nurses in the two medical services of the hospital where the investigation was allowed to take place.

\section{Study Protocol}

Data collection was conducted through the application of a self-administered questionnaire, developed for this research, which is composed by three parts: sociodemographic and professional characterization; the "Job Satisfaction Scale"(17); and the "Veiga Emotional Competence Scale"(18-19). The "Job Satisfaction Scale" was developed by the hospital where we collected the data, and is composed of 28 items, assessed on a 5-point Likert scale, in which 1 corresponds to "bad" and 5 to "excellent". This scale encompasses four dimensions: satisfaction with the hierarchical superior figure ("boss"), satisfaction with professional relations, satisfaction with the workplace quality, and satisfaction with continuous quality improvement. The total score was obtained by calculating the average of the items that are part of the scale, ranging from 0 to 5 points, so the higher the average achieved, the higher the job satisfaction. The internal consistency was evaluated by Cronbach's alpha coefficient, verifying that the scale, as a whole, has an adequate internal consistency index in the pre-test $(a=0,97)$ and in the post-test $(a=0,96)$. The "Veiga Emotional Competence Scale", adapted for nurses ${ }^{(19)}$, is composed of 85 items, rated on a 7-point Likert scale, in which 1 corresponds to "never" and 7 to "always". This scale consists of five domains: self-awareness, emotion management, self-motivation, empathy, and emotion management in groups. The total score is obtained by calculating the weighted average of the items that form the scale, ranging from 85 to 595 points, so the higher the weighted average achieved, the higher the emotional competence. The internal consistency was assessed by Cronbach's alpha coefficient, verifying that the scale, as a whole, has an adequate internal consistency index in the pre-test $(a=0,92)$ and the post-test $(a=0,94)$.

As for the data collection procedure and the implementation intervention, this study was composed of three key moments (pre-test; intervention; post-test). The first moment (pre-test) was carried out from October to December 2017 and integrated stages 1 and 2 of the SafeCare Model (application of the questionnaire to nurses prior to the implementation intervention, as well as the recognition of nurses' clinical supervision needs). Each nurse received the questionnaire in paper format, in a closed envelope. There was an explanation on the objective and procedure of the study and the nurses were asked to fill out the questionnaire. It was emphasized the nurses' voluntary participation in the study and we ensured that non-participation would not constitute a reason for any damage. In order to secure the anonymity of the answers, the nurses were informed not to put their names anywhere on the questionnaire. The identification of needs in clinical supervision was carried out through meetings with the nurses from the contexts. In the first meeting, nurses were asked to reflect on the current practices and the dynamics of the context in order to identify aspects that would require changes, emphasizing that clinical supervision needs could be personal, such as the acquisition of knowledge in a specific area or instrumental domain and, also, related to the dynamics of the care context itself. Nurses were asked to list the needs felt by each one of them individually in writing to ensure no discomfort. In the following meeting, the nurses handed in their individual list of clinical supervision needs to the main researcher.

In the second phase of the study, stage 3 of the SafeCare Model (implementation of the SafeCare Model) was conducted, which took place from January to December 2018 and included several activities. First, group training in Clinical Supervision was provided to all nurses of the context by the main researcher, addressing the following topics: concepts and history of clinical supervision; clinical supervision models, with emphasis on the SafeCare Model; supervisory relationship; personal and professional learning and development; innovation processes, care management, and leadership; quality of care and patient safety. Subsequently, clinical supervisors and supervised nurses were identified. Head nurses selected the clinical supervisors, taking into account a set of criteria defined by the researchers, which reflect what is recommended by scientific evidence ${ }^{(20)}$, namely: nurses who have had five or more years of professional experience in a care context; nurses who demonstrate interest and availability for the role; nurses who demonstrate involvement in the occupation; nurses who demonstrate critical thinking and interpersonal skills; nurses who are able to establish trusting relationships; nurses who are recognized by peers; be thoughtful and assertive; own a training/certification of clinical supervision competencies; nurses who are experienced in training processes. Still, in collaboration with the head nurses, we set up supervision teams in one clinical nurse supervisor ratio for eight to ten supervised nurses ${ }^{(21)}$. Finally, 
group supervision sessions were planned and scheduled, with a periodicity of one monthly session per supervision team, lasting 90 minutes. During the implementation of the SafeCare Model, we addressed the themes of professional satisfaction and emotional competence and also worked on the clinical supervision needs identified by the nurses, which were covered in the following domains: communication; emotion management; contractual indicators with the institution; care delivery; nursing information system records; and review of service protocols. The environment experienced in the supervision sessions was of interaction and sharing of experiences among nurses in order to foster team spirit and strengthen collective learning.

The third phase (post-test) integrated stage 4 of the SafeCare Model (assessment of results) and occurred from January to March 2019, with the application of the same questionnaire applied in stage 1 after the implementation intervention, to be able to objectify possible changes in the nurses' job satisfaction and emotional competence after the execution of the Model.

\section{Result analysis and statistics}

For data analysis, we used descriptive statistics and the nonparametric test for paired samples - Wilcoxon test (given the sample size and the type of study) in comparison the pre-test with the post-test, through the Statistical Package for the Social Sciences (SPSS) version 25.0, considering a significance level of 5\%.

\section{RESULTS}

The sample consisted of 28 nurses, most of whom are female ( $n=24 ; 85,7 \%$ ). Age ranges from 22 to 49 years, with the average age being 35 years ( $35 \pm 8$ ). Regarding the professional degree, most of the participants hold the title of nurse ( $n=23 ; 82,1 \%$ ), and only five $(17,9 \%)$ are expert nurses. The period of professional practice experience varies between 0 and 27 years, in which the average is approximately 11 years $(11 \pm 8)$.

Table 1 shows the results obtained in the pre-test and posttest regarding the total score and the four dimensions of the "Job Satisfaction Scale". In the pre-test and post-test, nurses showed moderate levels of job satisfaction, as well as in the remaining dimensions, except for the professional relationships dimension, which was slightly below moderate.

Table 1 - Descriptive statistics of nurses'job satisfaction in the pre-test and post-test $(\mathrm{N}=28)$, Porto, Portugal, 2017 and 2019

\begin{tabular}{|c|c|c|c|c|}
\hline & Minimum & Maximum & Mean & S.I.D.* \\
\hline \multicolumn{5}{|l|}{ Pre-test } \\
\hline Hierarchical Superior figure & 1.00 & 5.00 & 3.09 & 1.06 \\
\hline Professional relations & 1.33 & 5.00 & 2.43 & 0.76 \\
\hline Workplace quality & 1.67 & 5.00 & 2.75 & 0.74 \\
\hline Continuous quality improvement & 1.50 & 5.00 & 2.79 & 0.81 \\
\hline Job satisfaction (total) & 1.39 & 5.00 & 2.74 & 0.70 \\
\hline \multicolumn{5}{|l|}{ Post-test } \\
\hline Hierarchical Superior figure & 1.00 & 4.86 & 2.47 & 1.03 \\
\hline Professional relations & 1.33 & 3.56 & 2.37 & 0.59 \\
\hline Workplace quality & 1.67 & 4.00 & 2.73 & 0.67 \\
\hline Continuous quality improvement & 1.17 & 4.00 & 2.67 & 0.73 \\
\hline Job satisfaction (total) & 1.64 & 4.04 & 2.54 & 0.61 \\
\hline
\end{tabular}

Table 2 shows no statistically significant differences in the nurses' job satisfaction between the pre-test and the post-test. Regarding the four dimensions of job satisfaction, it was found that there is a statistically significant difference in the hierarchical superior figure $(z=-2,63 ; p=0,01)$. According to Table 1, nurses are more satisfied with their supervisor in the pre-test than in the post-test.

Table 2 - Comparison of nurses' job satisfaction between pre-test and post-test $(\mathrm{N}=28)$, Porto, Portugal, 2017 and 2019

\begin{tabular}{|c|c|c|c|}
\hline & $\begin{array}{l}\text { Mean } \\
\text { order }\end{array}$ & $z^{*}$ & $\boldsymbol{p}^{\dagger}$ \\
\hline $\begin{array}{l}\text { Post hierarchical superior figure } \\
\text { Pre-hierarchical superior figure }\end{array}$ & $\begin{array}{l}10.83 \\
13.68\end{array}$ & -2.63 & 0.01 \\
\hline $\begin{array}{l}\text { Post professional relations } \\
\text { Pre-professional relations }\end{array}$ & $\begin{array}{l}15.00 \\
12.56\end{array}$ & -0.65 & 0.52 \\
\hline $\begin{array}{l}\text { Post workplace quality } \\
\text { Pre workplace quality }\end{array}$ & $\begin{array}{l}12.61 \\
15.50\end{array}$ & -0.30 & 0.76 \\
\hline $\begin{array}{l}\text { Post Continuous quality improvement_Pre- } \\
\text { continuous quality improvement }\end{array}$ & $\begin{array}{l}18.50 \\
12.11\end{array}$ & -0.99 & 0.32 \\
\hline $\begin{array}{l}\text { Post Job satisfaction (total)__Pre-post Job } \\
\text { satisfaction (total) }\end{array}$ & $\begin{array}{l}12.27 \\
15.94\end{array}$ & -1.55 & 0.12 \\
\hline
\end{tabular}

Note: ${ }^{*} z=$ Wilcoxon Test; ${ }^{+} p<0.05$

Table 3 - Descriptive statistics of the nurses' emotional competence profile in the pre-test and post-test $(\mathrm{N}=28)$, Porto, Portugal, 2017 and 2019

\begin{tabular}{lcccc}
\hline & Minimum & Maximum & Mean & S.I.D.* \\
\hline Pre-test & & & & \\
$\quad$ Self-awareness & 51 & 99 & 77.43 & 9.93 \\
Emotion management & 36 & 81 & 57.54 & 10.06 \\
Self-motivation & 39 & 93 & 67.32 & 11.72 \\
Empathy & 41 & 68 & 53.54 & 7.45 \\
Emotion management in groups & 45 & 82 & 61.14 & 9.15 \\
Emotional Competence (total) & 232 & 380 & 316.96 & 35.69 \\
Post-test & & & & \\
Self-awareness & 55 & 96 & 75.61 & 10.90 \\
Emotion management & 41 & 79 & 59.82 & 9.40 \\
Self-motivation & 45 & 95 & 67.36 & 10.75 \\
Empathy & 34 & 73 & 54.32 & 10.35 \\
Emotion management in groups & 36 & 84 & 60.32 & 12.68 \\
Emotional Competence (total) & 217 & 394 & 317.43 & 41.62 \\
\hline
\end{tabular}

Note: *S.I.D. = Standard Deviation.

Table 4 - Comparison of nurses' emotional competence profile between pre-test and post-test $(\mathrm{N}=28$ ), Porto, Portugal, 2017 e 2019

\begin{tabular}{llll}
\hline & $\begin{array}{l}\text { Mean } \\
\text { order }\end{array}$ & $z^{*}$ & $\boldsymbol{p}^{\dagger}$ \\
\hline Post Self-Awareness_Pre Self-Awareness & 12.71 & -0.58 & 0.56 \\
& 14.18 & & \\
Post Emotion management__ & 13.68 & -0.78 & 0.44 \\
Pre Emotion management & 12.14 & & \\
Post Self-motivation_Pre Self-motivation & 14.00 & -0.51 & 0.61 \\
& 14.00 & & \\
Post Empathy_Pre Empathy & 14.73 & -0.41 & 0.68 \\
& 14.23 & & \\
Post Emotion management in groups_ & 16.36 & -0.52 & 0.60 \\
Pre Emotion management in groups & 13.29 & & \\
Post Emotional Competence (total)_ & 15.31 & -0.09 & 0.93 \\
Pre Emotional Competence (total) & 13.80 & & \\
\hline Note: ${ }^{*} z=$ Wilcoxon Test; ${ }^{\dagger} p<0.05$. & & &
\end{tabular}


Table 3 shows the results obtained in the pre-test and posttest regarding the total score and the five domains of the "Veiga Emotional Competence Scale". It was found that nurses perceived themselves as having reduced self-confidence before and after the implementation of the SafeCare Model, as also in the domains of self-awareness, emotion management, and self-motivation. In turn, nurses perceived themselves with a slight level of empathy in both stages, as well as in the domain of emotion management in groups.

Table 4 shows no statistically significant differences in the nurses' emotional competence profile before and after the intervention. It was also found that there are no statistically significant differences between the pre-test and the post-test in any of the domains of emotional competence assessed.

\section{DISCUSSION}

Concerning professional satisfaction, there was a statistically significant decrease with the hierarchical superior figure after implementing the SafeCare Model. These results may be explained by the fact that there was a change of head nurse in one of the services during the intervention implementation. Head nurses assume a primary relevance in establishing strategies that can improve the work environment and promote job satisfaction among nurses ${ }^{(10)}$. Indeed, the role of the hierarchical superior figure is fundamental not only for the human management and material resources but also for the communication's effectiveness and inter-relationship among professionals, particularly in what concerns conflict management ${ }^{(22)}$. No statistically significant differences were found in the remaining dimensions of nurses'job satisfaction before and after the implementation of the SafeCare Model. These results differ from the other study, in which, after the implementation of a clinical supervision model, nurses reported feeling higher professional satisfaction ${ }^{(3)}$. In this study, some factors may have contributed to the results obtained, such as the change of the head nurse in the services where the intervention took place and the composition change of the nursing teams, which led to a more significant overload for the members who remained in the team and completed the study. The professional context assumes a central place in the intervention in clinical supervision, whose set of interactions mediates the remaining SafeCare Model axes ${ }^{(6)}$. In fact, the mobility of nurses influences the institutional environment as this commonly causes the loss of experienced professionals, which consequently leads to an increase in work overload, decrease in job satisfaction, and increase in burnout ${ }^{(23)}$. Nevertheless, after implementing the SafeCare Model, we noticed that the nurses maintained moderate levels of job satisfaction obtained in the pre-test, despite all the discomfort that occurred in the context.

Regarding the emotional competence profile, it was found that there were no statistically significant differences in any of the domains assessed. The shortage of nurses is a conditioning factor for their emotional response ${ }^{(24)}$. As previously mentioned, in this study, there was a decrease in the number of nurses per service, and in most cases, new nurses were not immediately hired, which caused the nursing teams not to include the appropriate number of nurses to provide excellent nursing care. These results can also be explained by the fact that it only mentioned emotional competence in one of the supervision sessions and that there was not enough time to dynamize, as much as it should have been, practical exercises in order to enhance the development of skills related to emotion management and conflict management. Additionally, individual supervision sessions could have proved to be more effective in terms of the intervention in emotional competence, to the extent that they would allow nurses to be truly genuine about their difficulties and not feel embarrassed by the presence of the other nurses from the supervision team. Another strategy could be to request interdisciplinary collaboration from other professionals, namely psychologists, who would participate in the supervision sessions and enhance the gains in terms of emotion and communication management.

This study encompasses essential and innovative aspects. In fact, the evidence suggests that, although there are clinical supervision models with a positive impact on health institutions, nurses, and patients, their operationalization is not clear, making it difficult to replicate them in other contexts ${ }^{(1,5)}$. This is the first article to assess the impact of implementing the SafeCare Model on professional satisfaction and emotional competence. Since the SafeCare Model is a new model of clinical supervision, it is vital to apply it to practice settings to understand its effectiveness and, consequently, to suggest changes to maximize the results that may arise from its implementation. Scientific evidence shows that clinical supervision is essential to support nurses and help them develop and improve their practice and that the application of a clinical supervision model is necessary to achieve this purpose ${ }^{(25)}$. However, there are personal and institutional barriers to the implementation of clinical supervision models ${ }^{(26)}$. In order to overcome these barriers, it is crucial to have a management partnership and nursing leadership with joint responsibilities ${ }^{(27)}$ that are present during the development, implementation, coordination, and evaluation of the implemented supervision model. This partnership is essential to bind the healthcare institution in ensuring necessary conditions that allow the implementation of the clinical supervision model to proceed without significant changes in its context. During the course of the current study, several changes occurred in the context of care practice. For future studies, we suggest that there should be a more effective link from the health institution to minimize the change in the implementation context, since the contexts where there are the best results in terms of effectiveness of clinical supervision model implementation are those where people and the institution are actively involved in a previous phase ${ }^{(28)}$.

There is another suggestion regarding the clinical supervisors' choice. In this study, the clinical supervisor's choice was made by the head nurses. However, scientific evidence indicates that clinical supervisors should be chosen by their peers, which is crucial for the successful implementation of clinical supervision ${ }^{(29)}$. We also found that the number of hours spent in the group supervision sessions to work on job satisfaction and emotional competence was insufficient. It is suggested that future research should increase the number of hours spent on these variables. It is difficult to establish an efficient clinical supervision practice in the absence of adequate training on the subject ${ }^{(1)}$. In this sense, we suggest that, in the future, training in clinical supervision should first be provided at an institutional level and, subsequently, to the nurses 
participating in the study so that they are already aware of this topic. Thus, the opportunity is created to more quickly understand that the implementation of the SafeCare Model may bring benefits in terms of job satisfaction, emotional competence, and the promotion of the safety and quality of nursing care.

\section{Limitations of the Study}

It is also necessary to overcome some limitations of the study, namely the absence of a control group. Another limitation is that the study sample is small $(n=28)$ and includes only nurses from medical services. There were significant changes in the context where we implemented the model that could not be controlled, and that may have produced changes in the results obtained, as previously mentioned.

\section{Contributions to the Field}

There are few quantitative studies on clinical supervision, and it is necessary to conduct them in order to promote the development and construction of a knowledge base in this area ${ }^{(1)}$. In fact, there is a lack of evidence on robust models of clinical supervision application, regarding research on its implementation, and also over training ministered to its participants ${ }^{(7)}$. This study intended to respond to the considerations mentioned above, constituting an essential contribution to the advancement of scientific knowledge on clinical supervision in Nursing.

\section{CONCLUSION}

Scientific evidence have shown that there are advantages in implementing clinical supervision models for nurses, users, and health institutions. Theoretically, the SafeCare Model should generate both gains in supervision and gains in health. This model should be useful for supervisory practice as it focus on responding to the nurses' needs, allowing them to become more capable for professional practice, thus increasing their satisfaction and attachment to the profession. As for health gains, it would also bring benefits due to its high potential for the design of quality care. Although in this study the implementation of the SafeCare Model did not have an impact on the nurses'job satisfaction and emotional competence profiles, these results is justified due to the profound and diverse changes that occurred in the context, as well as some factors intrinsic to the Model (number of hours spent addressing job satisfaction and emotional competence, selection of clinical nurse supervisors, among others). Indeed, there are personal factors (fear of change, lack of confidence and knowledge/competence, lack of knowledge about clinical supervision, and erroneous beliefs) and institutional factors (professional and political conflicts, lack of time/resources issues, rotating/disruptive shifts) that are barriers to the implementation of clinical supervision models. In terms of personal factors, we suggest that future studies should further clarify the benefits of clinical supervision by providing a more significant number of training hours in this area, as well as providing more training to clinical nurse supervisors to enhance the performance of their role; from the point of view of institutional factors, there should be a more useful link to the implementation of the SafeCare Model, in order to ensure the necessary conditions for the clinical supervision model to occur without major changes in its context. It is suggested the application of the SafeCare Model in different contexts (hospital and community), as well as in different parts of the country, because this is the only way to evaluate the actual effectiveness of the model and the benefits that may result from it.

\section{REFERENCES}

1. Cutcliffe J, Sloan G, Bashaw M. A systematic review of clinical supervision evaluation studies in nursing. Int J of Ment Health Nurs. 2018;27(5):1344-63. https://doi.org/10.1111/inm.12443

2. Ordem dos Enfermeiros. Caderno temático - Modelo de desenvolvimento profissional: fundamentos, processos e instrumentos para a operacionalização do Sistema de Certificação de Competências. Lisboa: Ordem dos Enfermeiros; 2010.

3. Gonge $\mathrm{H}$, Buss $\mathrm{N}$. Is it possible to strengthen psychiatric nursing staff's clinical supervision? RCT of a meta-supervision intervention. J Adv Nurs. 2015;71(4):909-21. https://doi.org/10.1111/jan.12569

4. MacCulloch T, Shattell M. Clinical supervision and the well-being of the psychiatric nurse. Issues Ment Health Nurs. 2009;30(9):589-90. https://doi.org/10.1080/01612840902954541

5. Pollock A, Campbell P, Deery R, Fleming M, Rankin J, Sloan G, et al. A systematic review of evidence relating to clinical supervison for nurses, midwives and allied health professionals. J Adv Nurs. 2017;73(8):1825-37. https://doi.org/10.1111/jan.13253

6. Carvalho A, Barroso C, Pereira M, Teixeira A, Pinho F, Osório M. Implementação de um modelo de supervisão clínica em enfermagem. Porto: Uniarte Gráfica; 2019

7. Snowdon D, Leggat S, Taylor N. Does clinical supervision of healthcare professionals improve effectiveness of care and patient experience? a systematic review. BMC Health Serv Res. 2017;17(1):786. https://doi.org/10.1186/s12913-017-2739-5

8. Cruz S, Carvalho A, Sousa P. Clinical supervision and emotional intelligence capabilities: excellence in clinical practice. Proced Social Behav Sciences. 2015;171:153-57. https://doi.org/10.1016/j.sbspro.2015.01.101

9. Temesgen $\mathrm{K}$, Aycheh M, Leshargie C. Job satisfaction and associated factors among health professionals working at Western Amhara Region, Ethiopia. Health Qual Life Outcomes. 2018;16(1):16-65. https://doi.org/10.1186/s12955-018-0898-7

10. Silva C, Potra T. Job satisfaction of nurses: a Scoping review. Pens Enferm. 2016;20(2):33-50. https://doi.org/10.1016/j.ijnurstu.2019.01.011 
11. Boamah S, Read E, Laschinger H. Factors influencing new graduate nurse burnout development, job satisfaction and patient care quality: a time-lagged study. J Adv Nurs. 2017;73(5):1182-1195. https://doi.org/10.1111/jan.13215

12. Lopes P. Emotional intelligence in organizations: bridging research and practice. Emot Review. 2016;8(4):316-21. https://doi. org/10.1177/1754073916650496

13. Goleman D. Emotional Intelligence. Lisboa: Temas e Debates; 2003

14. Veiga-Branco A. Competência emocional. In: Jardim J, Franco J. Dicionário de Educação para o Empreendedorismo. Lisboa: Gradiva; 2019. p. 132-35

15. Raghubir A. Emotional intelligence in professional nursing practice: a concept review using Rodgers's evolutionary analysis approach. Int J Nurs Sciences. 2018;5(2):126-30. https://doi.org/10.1016/j.ijnss.2018.03.004

16. Wallbank S, Hatton, S. Reducing burnout and stress: the effectiveness of clinical supervision. Community Pract. 2011;84(7):31-35

17. Gabinete da Qualidade da ULSM. Documento Normativo nº 2482.1 de 17 de outubro. Avaliação da satisfação dos profissionais da ULSM. 2014

18. Veiga-Branco A. Emotional Competence. Coimbra: Quarteto; 2004

19. Vilela C. Inteligência Emocional - Um recurso para Enfermeiros: Contributos para a gestão, formação e desenvolvimento de competências emocionais. Mauritius: Novas Edições Académicas; 2018

20. Gazzola N, Stefano J, Thriault A, Audet C. Learning to be supervisors: A qualitative investigation of difficulties experienced by supervisors-intraining. J Clin Superv. 2013;32(1):15-39. https://doi.org/10.1080/07325223.2013.778678

21. Ducat W, Kumar S. A systematic review of professional supervision experiences and effects for allied health practitioners working in nonmetropolitan health care settings. J Multidiscip Healthc. 2015;26(8):397-407. https://doi.org/10.2147/JMDH.S84557

22. Ferreira C, Fernandez R, Anes E. Job satisfaction of nurses working in hospital units of northen Portugal. Rev Enf Ref. 2017;4(15):109-18. https://doi.org/10.12707/RIV17043

23. Gifford W, Davies B, Edwards N, Griffin P, Lybanon V. Sustaining knowledge transfer through leadership. Worldviews Evid Based Nurs. 2007;4(3):126-45. https://doi.org/10.1111/j.1741-6787.2007.00095.x

24. Escribà V, Más $P$, Cárdenas E, Burguete R, Fernández R. Work-related stress factos and the psychological well-being of hospital nurses. Rev Enferm. 2000;23(7-8):506-11

25. Dilworth S, Higgins I, Parker V, Kelly B, Turner J. Finding a way forward: a literature review on the current debates around clinical supervision. Contemp Nurse. 2013;45(1):22-32. https://doi.org/10.5172/conu.2013.45.1.22

26. Koivu A, Saarinen P, Hyrkas K. Who benefits from clinical supervision and how? The association between clinical supervision and the workrelated well-being of female hospital nurses. J Clin Nurs. 2012;21(17-18):2567-78. https://doi.org/10.1111/j.1365-2702.2011.04041.x

27. McKenna B, Thom K, Howard F, Williams V. In search of a national approach to professional supervision for mental health and addiction nurses: the New Zealand experience. Contemp Nurse. 2010;34(2):267-76. https://doi.org/10.5172/conu.2010.34.2.267

28. Buus N, Lynch L, Gonge H. Developing and implementing 'meta-supervision' for mental health nursing staff supervisees: opportunities and challenges. Cog Behav Therap. 2016;9(22):323-34. https://doi.org/10.1017/S1754470X15000434

29. Edwards D, Cooper L, Burnard P, Hannigan B, Juggesur T, Adams J et al. Factors influencing the effectiveness of clinical supervision. J Psychiatr Ment Health Nurs. 2005;12(4):405-14. https://doi.org/10.1111/j.1365-2850.2005.00851.x 